\title{
Análise do programa de qualificação profissional de agricultores - Emater, sob a perspectiva midiática
}

\author{
Analysis of the program of professional qualification of farmers - emater, under the perspective midiática \\ Jordana Georgin', Laudison Lazzari², lolanda Lopes ${ }^{3}$ \\ 'Mestranda em engenharia ambiental, Universidade Federal de Santa Maria \\ ${ }^{2}$ Engenheiro agrônomo, Universidade Federal de Santa Maria \\ ${ }^{3}$ Mestranda no programa de extensão rural, Universidade Federal de Santa Maria
}

\section{Resumo}

A Emater é um órgão do governo estadual que tem como objetivo desenvolver o meio rural por meio de programas, sempre dando prioridade e subsídios para os pequenos agricultores, objetivando manter eles no campo, bem como as suas gerações futuras. Mediante isso a Emater criou o Programa de qualificação profissional de agricultores, cujo abrange inúmeras cidades do Estado com cursos voltados as mais diversas áreas, sempre aliando a prática com a teoria, por meio de uma linguagem clara e comum, o extensionista busca trazer novas formas de se produzir, gerando uma maior renda para os produtores. Todo esse processo se da de forma lenta, e alinhando a realidade local da comunidade. Com um poder de mídia primária forte, e clara o programa vem trazendo resultados positivos, e se mostrando extremamente eficaz no que diz respeito a trazer novas fontes de renda com vista a manter o produtor rural no campo.

Palavras-chaves:Emater; Produtor rural; Extensionista.

\begin{abstract}
The Emater is an organ of the state government that has as objective develops the rural way through programs, always giving priority and subsidies for the small farmers, aiming they maintaining in the field, as well as his future generations. By means of that the Emater created the Program of professional qualification of farmers, whose it includes countless cities of the State with opposite courses more several areas, when the practice is always allying with the theory, through a clear and common language, the extensionista looks to bring the new forms of being produced, producing a bigger income for the producers. All this process if of that of slow form, and aligning the local reality of the community. With a power of strong, and clear primary media the program is bringing positive results, and showing extremely efficiently what concerns bringing new fountains of income with sight to maintain the rural producer in the field.
\end{abstract}

Keywords: Emater; Rural producer, Extensionista. 


\section{INTRODUÇÃO}

A Empresa de Assistência Técnica e Extensão Rural (Emater) é um órgão do governo estadual que visa promover o desenvolvimento rural sustentável em conjunto com ações de assistência técnica e extensão rural, por meio de processos educativos e participativos, tendo como finalidade o fortalecimento da agricultura familiar levando uma melhoria da qualidade da vida da população no campo. No estado do Rio Grande do Sul é inquestionável a importância do setor rural no conjunto do desenvolvimento sócio-econômico. Cerca da metade da riqueza, gerada em solo gaúcho, provêm da agropecuária. De seus diversos componentes, $55 \%$ são oriundos da agricultura familiar, cuja função vital é de ser produtora de alimentos (EMATER, 2009).

No intuito de levar mais informações aos agricultores à Emater desenvolveu em 1995 o programa de qualificação profissional de agricultores, que por meio de processos educativos e participativos leva informações e conhecimentos técnicos mediante profissionais habilitado.

O Programa de Qualificação de Agricultores tem por objetivo desenvolver, através de cursos e outros eventos de qualificação, a capacidade de gestão dos agricultores nas áreas de produção, transformação e beneficiamento de produtos, visando à agregação de renda e ao aumento da competitividade, pela adição de valor à produção e pelo fortalecimento dos processos organizativos (EMATER, 2008).

Estes profissionais são formados em diversas áreas e atuam como agentes de desenvolvimento rural, levando ás famílias rurais tecnologias mais produtivas, com menores custos, e mais rentáveis, fazendo com que essas famílias possam continuar vivendo no meio rural. O programa tem dois cenários, o que se desenvolve nas comunidades, e o que se desenvolve nos centros de formação.

Nas comunidades o extensionista usa uma metodologia mais abrangente, por meio de demonstrações práticas, dias de campo para demonstrar técnicas mais adequadas levando os bons resultados obtidos, por meio de trabalhos individualizados realizados em outras propriedades. Já nos centros de formação são realizadas atividades que requerem um conhecimento mais aprofundado, normalmente são feitas apresentações em Power point (referencial teórico), relacionados a temas específicos, e muitas aulas práticas, havendo nesses centros cursos mensais com carga horária amplificada e intensiva, essas unidades didáticas possuem as estruturas adequadas para o produtor reproduzir a atividade que lhe foi apresentada, como por exemplo além da sala de aula para o curso de gado de leite, a área dispõem de um local de pastagem, animais, e equipamentos instalados para o produtor poder praticar, já no curso de massas e pães o aluno dispõem de um lugar com máquinas e produtos necessários para a aplicação prática das receitas.

O exercício da prática é o principal processo de aprendizagem nesses centros, pois o produtor exercita junto com o grupo e com o instrutor capacitado (Figura 1).

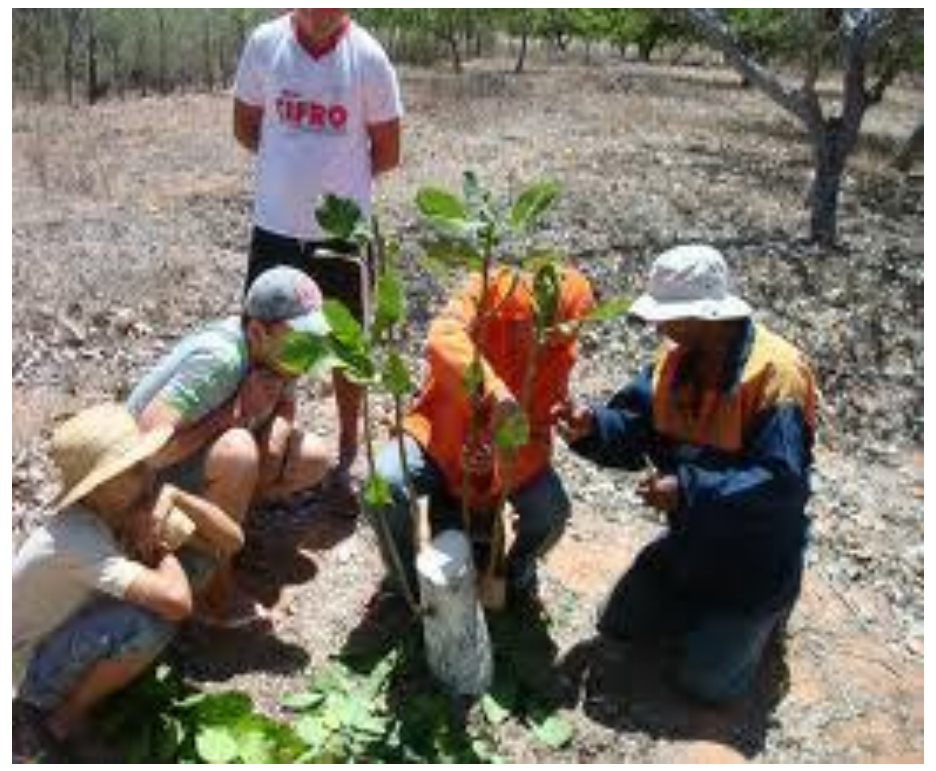

Figuras 1 - Produtor durante o curso exercitando seus conhecimentos com o extensionista.

Fonte - EMATER. 
Logo após esses cursos, á uma continuidade de atendimento ao produtor por meio de visitas técnicas, exercidas pelos extensionistas municipais, o qual irá ajudar na aplicação dos conhecimentos adquiridos em sua propriedade (Figura 2). Os centros disponibilizam aos cursistas além de salas equipadas, alimentação e alojamento para os produtores mais distantes, agregando um intercâmbio por meio da troca de experiências entre os colegas da turma, trazendo a possibilidade de pensar e refletir, á distância o seu empreendimento. O profissional responsável em transmitir o conhecimento é qualificado não só tecnicamente, mas também didaticamente, pois falam e entendem a linguagem dos participantes, estes fornecem aos produtores um material didático completo, e de linguagem simples, a fim de facilitar o entendimento dos participantes.

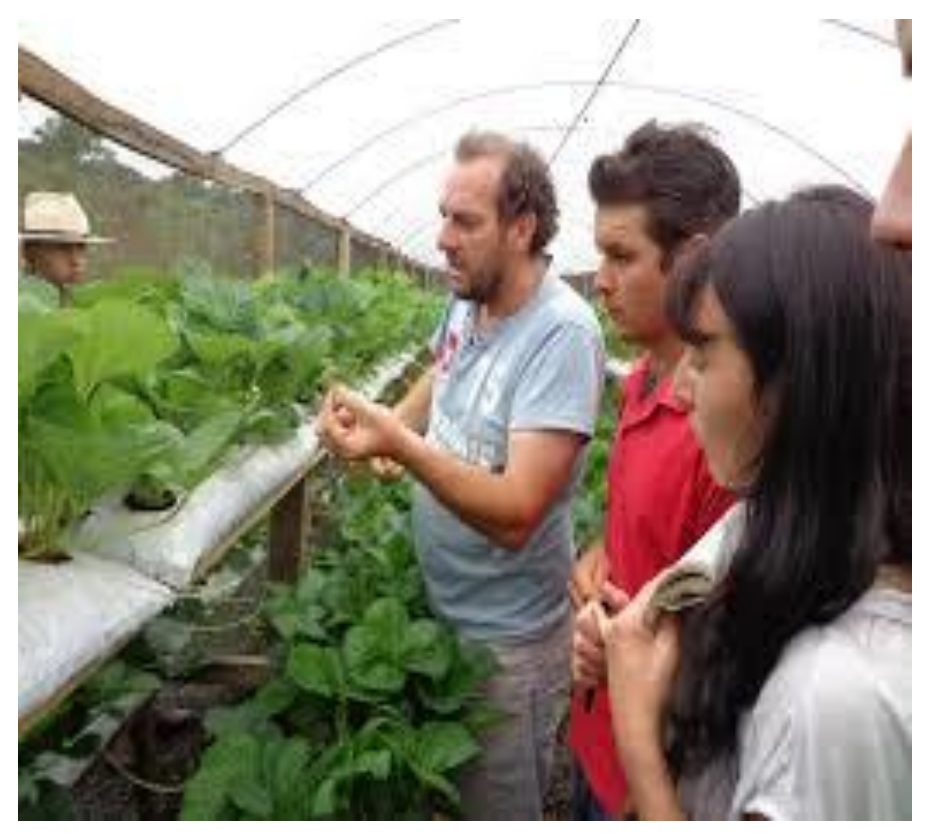

Figuras 2 - Acompanhamento deste profissional a propriedade rural.

Fonte-EMATER.

Atualmente a Emater possui sete centros em funcionamento em sete municípios do estado do Rio Grande do Sul (Bom Progresso, Erechim, Caxias do Sul, Canguçu, Montenegro, Teutônia e Nova Petrópolis). Como exemplo iremos falar do CETRE, centro de formação de agricultores de Erechim, este está locado junto ao colégio agrícola Ângelo Emílio Grando, o qual possuí convênio com a secretaria estadual da agricultura e de educação e cultura. No CETRE são ministrados cursos de bovinocultura de leite, secagem e armazenagem de grãos, panificação e processamento de farináceos, citricultura e produção artesanal de bolos e bolachas, massas frescas, salgados e gestão de agroindústrias. As inscrições dos cursos são realizadas diretamente na Emater de casa município sendo que os valores de cada curso variam em torno de 150,00 a 200,00 reais, para esta região citada como exemplo. Os cursos têm uma carga horária de 40 horas, em média.

Para o êxito dos projetos e dos objetivos propostos em cada eixo, desenvolveram-se, reuniões, visitas, diagnósticos, levantamento de necessidades das famílias, compilação de dados, elaboração conjunta com as famílias envolvidas nas atividades a serem executadas, bem como o plano de ação, aplicação de diagnóstico rápido participativo, elaboração de planos de crédito para acesso às políticas públicas, além de visitas técnicas e prestação de orientações e acompanhamento técnicos. As ações foram desenvolvidas de forma continuada, com o envolvimento dos usuários, sendo eles considerados os protagonistas. Foram envolvidas diferentes entidades no decorrer do desenvolvimento dos projetos, de acordo com a realidade de cada município (EMATER, 2008).

A avaliação e o monitoramento das atividades foram feitos ao longo do ano, através de processos de participação dos envolvidos, possibilitando ajustes e alterações, quando necessário, para vencer desafios durante o desenvolvimento e a execução dos métodos aplicados nos cursos, isso foi possível, pois no final de todos os cursos a Emater adquiriu o cadastro de cada produtor rural, bem como as 
atividades exercidas por eles, para que assim com o passar do tempo o extensionista possa seguir acompanhando esses produtores com visitas periódicas, o qual procura-se dar este acompanhamento, a fim de se obter um sucesso econômico no investimento feito na propriedade.

Mediante isso o objetivo do estudo foi realizar uma análise dos resultados já obtidos por meio destes programas, bem como uma perspectiva midiática de como estes conhecimentos são repassados, comparando todo esse processo de aprendizagem com alguns escritores da literatura midiática.

\section{MATERIAIS E MÉTODOS}

O presente estudo foi realizado por meio de uma revisão de literatura, em relação a obras relacionadas á midiatização global, bem como a análise de inúmeros relatórios elaborados pela EMATER, contendo todo o processo didático realizado nesses centros, bem como uma analise da postura adota pelos profissionais, extensionista, os quais são considerados dentro do programa como agentes participativos e habilitados a se comunicar com a cultura local, além dos resultados e os impactos que estes programas vêm trazendo as populações rurais.

Todo esse estudo foi elaborando analisando o programa a âmbito geral, logo não foi observado um centro em uma determinada cidade específica, todos foram analisados em conjunto, e em diferentes regiões, isto foi estabelecido para poder ter uma visão mais ampla das dimensões desses programas, visto que os impactos analisados não se alteram muito de região para região.

A análise comparativa com o suporte midiático foi empregado no estudo para se ter uma dimensão de como isso é aplicado no meio rural, e o quanto isto influência no poder de aprendizado dos produtores, isso foi relacionado com alguns autores para que se possa ser observado como está midiatização é descrita e analisada na literatura.

\section{RESULTADOS E DISCUSSÕES}

Os meios de comunicação com o passar do tempo tornaram-se cada vez mais robotizados, e com o aumento do consumismo mundial essa tecnologia difundiu-se ainda mais. É comum nos depararmos com situações em que grupos de amigos estão conectados aos seus aparelhos celulares, um ambiente onde isso fica muito evidente são os shoppings centers, nota-se que o diálogo é cada vez menos frequente. Essa realidade é caracterizada como midiatização terciária que segundo Baitello junior apud Pross (1971:226) é definida como, "meios de comunicação que não podem funcionar sem aparelhos tanto do lado do emissor quanto do lado do receptor". Analisando esse tipo de mídia, pode-se perceber que a sua utilização no espaço rural brasileiro ainda é pequeno, claro que se tratando de espaços rurais familiares e não de regiões onde se desenvolve o agronegócio. Apesar de que, esse tipo de mídia vem ganhando seu espaço nesses territórios particulares, ainda assim a mídia primária é dominante nesse cenário, contudo o digital acaba servindo como suporte de informações, notícias e comunicação com parentes e amigos distantes.

Toda comunicação humana começa na mídia primária, na qual os participantes individuais se encontrem cara a cara e imediatamente presentes com seu corpo; toda comunicação humana retornará a este ponto. (Pross, 1971:128)

Mediante essa realidade a atividade de qualificação dos agricultores desenvolvida pela Emater caracteriza-se principalmente pelo processo de midiatização primária, por meio de conversas e aulas práticas, o extensionista transfere informações ao mesmo tempo em que recebe e esclarece dúvidas ao produtor.

Além da utilização em sua maioria da midiatização primaria, o profissional ainda utiliza como suporte de auxilio a midiatização secundária sendo este um apoio de ensino feito por meio do uso de escritas, desenhos, reto projetores, figuras, apostilas, banners, panfletos entre outros.

A mídia secundária é constituída, por "aqueles meios de comunicação que transportam a mensagem ao receptor, sem que este necessite um aparato para captar seu significado. (BAITELLO 


\section{JUNIOR apud PROSS, 1971:128).}

Apesar da midiatização terciária não apresentar grande utilização entre os agricultores, para o extensionista ela serve de aporte para a facilitação nesse processo de transição de informação.

A mídia terciária, diz Pross, "são aqueles meios de comunicação que não podem funcionar sem aparelhos tanto do lado do emissor quanto do lado do receptor" (BAITELLO JUNIOR apud PROSS, 1971:226).

A utilização da midiatização primaria no meio didático é imprescindível, principalmente em espaços rurais, pois proporciona um maior entendimento, bem como facilita muitas vezes a memorização por parte do aluno, logo o uso de vídeos, notebook, vídeos, aparelho celulares entre outros, torna-se um grande aliado do extensionista nesses centros. Fazendo uso desses meios juntamente com um diálogo próprio do local e simples, o profissional tende a ter grande sucesso na transmissão do seu conhecimento. A midiatização primária sofre uma grande influência do meio social e cultural, assim é de extrema importância o extensionista procurar empregar em suas falas uma linguagem simples e comum, facilitando a aprendizagem do publico em geral.

Em sua obra "Pedagogia do Oprimido", Paulo Freire retrata bem essa realidade, apresentando a dialogicidade como temática central, revelando o dialogo como a essência da educação, uma prática libertadora, evidenciando o quão importante é o desenvolvimento do diálogo no processo educativo. Como a comunicação é expressa pela palavra e pela ação, estes programas de qualificação tem uma grande ligação com esta obra neste sentido, em que a ênfase das aulas é o ensinar fazendo, alienando a prática com a teoria, isso facilita o processo de educação. Na obra o autor diz que é isso que dá sentido ao mundo em que os homens vivem e se relacionam.

Daí que, para esta concepção como pratica da liberdade, a sua dialogicidade comece, não quando o educador-educando se encontra com os educandos-educadores em sua situação pedagógica, mas antes quando aquele se pergunta em torno do que vai dialogar com estes. Esta inquietação em torno do conteúdo do dialogo é a inquietação em torno do conteúdo programático da educação. (FREIRE, 1987, p.47)

O diálogo entre educador-educando começa em seu planejamento do conteúdo programático, quando questiona o que vai refletir com seus alunos. Porem o autor afirma que isso só se dá em sua plenitude se esse conteúdo não estiver dissociado do cotidiano dos mesmos. E isso é extremamente presente nestes cursos, aonde a todo o momento o extencionista relaciona o aprendizado com o cotidiano dos agricultores, havendo uma total relação com o que eles vivem no mundo rural estabelecendo uma conexão real.

Paulo Freire elenca os principais elementos que compõem a ação dialógica, que são a colaboração, a união, a organização e a síntese cultural. A colaboração do diálogo tem como objetivo o entendimento e o respeito à culturalidade do individuo, este ponto é fundamental nestes centros de ensino, pois o extencionista procura moldar-se aos costumes e a forma de se comunicar do agricultor. Outro fator importante é a união da massa oprimida, que no caso seria composta pelos agricultores e o próprio extencionista que busca manter isso para que assim se crie um maior poder de transformação, isso se da pela organização gerando uma união das massas. O autor coloca isso como um sinal de liberdade para os oprimidos, pois todo esse processo de síntese cultural se fundamenta na compreensão e confirmação da dialeticidade permanência e mudança, que compõem toda a estrutura social presente no espaço rural.

Ao analisar a temática do livro de Paulo Freire, observa-se que o autor afirma a importância do homem saber de sua existência no mundo, bem como o quão relevante é esta aceitação, tornandose capaz de fazer a sua história e tendo capacidade para isso, independente da sua posição social ele tem total controle sobre si, esses fatores favorecem a dinâmica do aprender sem deixar ser oprimido. Porém o autor adverte que todo esse processo de transformação de massas, por meio do processo de educar ensinando, deve ser feito de forma lenta e gradual, pois só assim se evitara gerar novos seres oprimidos. Esses pontos são bem visíveis nos programas de qualificação da Emater, visto que sempre o aprendizado se da em conjunto e o educador sempre adequa a cultura das massas rurais, fazendo 
com que o agricultor não se sinta inferior e sempre mantendo a sua realidade presente.

No mesmo contexto de Freire, a obra de Márcio Simeone Henriques está relacionado aos interesses da Emater em transformar a realidade desses pequenos agricultores, por meio da mobilização de pequenas massas presente nos centros de qualificação.

De acordo com Henriques (2004) a mobilização social pode ser compreendida como a reunião de sujeitos que pretendem resolver problemas e transformar uma dada realidade, em relação a uma causa que possa ser considerada de interesse público. Consequência da emergência de sociedades complexas é uma mudança nas próprias formas através das quais os sujeitos se mobilizam, que passam a requerer novas estratégias (Henriques et. al., 2004).

$\mathrm{O}$ autor menciona diferentes movimentos ou projetos mobilizadores que competem entre si pela atenção dos cidadãos, esses são projetos de mobilização que são realizados por meio da iniciativa isolada, porém existem os que procuram articular-se com outros que tem a mesma finalidade social ou conexas, e é neste cenário que se enquadra o programa de qualificação de agricultores da Emater, sempre articulando o ensinar ao homem ou a mulher, como forma de unir o conhecimento e aplicar a realidade local em proposito de um bem social, e a uma melhor qualidade de vida no campo. É neste contexto que surgem redes de colaboração e solidariedade, compostas por agentes de mobilização diversos, sejam do Estado, de empresas ou da sociedade civil. Este formato pressupõe o estabelecimento de formas de cooperação entre estes agentes de modo a potencializar as suas ações e o seu poder de intervenção numa realidade social (Henriques, S. H, 2002).

As atividades desenvolvidas pelos extensionistas não deixam de formar uma rede de colaboração, na qual as atividades de um agente se fortalecem com a atividade dos demais, de forma a potencializar e fortalecer as mesmas, implicando diretamente em um maior impacto social.

Uma configuração em rede dos movimentos sociais e dos projetos mobilizadores pressupõe um intenso intercâmbio de informações, que possibilita uma produção contínua e conjunta de conhecimentos acerca das causas a que se referem e das causas correlatas. Por este motivo, esta metodologia de trabalho tem incorporado, cada vez mais, a noção de "ganho epistêmico", pressupondo-se que estes movimentos não se restringem ao ativismo, mas, por meio de sua própria ação, configuram "redes de aprendizagem", sendo capazes de, ao assimilar novos conhecimentos advindos de sua experiência, adaptar-se continuamente à velocidade das transformações e à dinâmica das lutas sociais (Henriques, S. H, 2002).

Este ganho epistêmico está presente neste processo, pois não perdem a características de centros de redes de aprendizagem, visto que ao mesmo tempo englobam um referencial teórico é possível assimilar novos conhecimentos provenientes da experiência que estes produtores já possuem, onde o papel do extencionista é sempre buscar relacionar a teoria com a pratica cotidiana dos alunos.

Por fim, considere-se ainda que um projeto mobilizador necessita produzir grande volume de informação qualificada, de modo a fazer com que os conhecimentos produzidos e acumulados possam circular convenientemente entre os diversos atores e de modo a instruir a ação. Consideramos informação qualificada aquela que informa e orienta de modo prático, que permite aos sujeitos saber o que fazer e como se posicionar dentro de movimento / projeto (Henriques, S. H, 2002).

Levando em consideração o que o autor trás como pontos importantes para se tornar um projeto mobilizador, pode-se dizer que estes centros geram e transmitem aos agricultores um grande volume de informações qualificadas, pois são feitas por profissionais especializados, que oferecem aporte para que essas informações circulem entre os ouvintes e assim a sua aplicação na prática, sempre orientando, estabelecendo um vinculo com os agricultores desde o ensinar, o aplicar, e estes pontos como mencionados acima são importantes para que o projeto tenha um impacto social relevante.

Diante dos desafios de mobilizar os sujeitos no cenário contemporâneo, torna-se cada vez mais evidente a necessidade de que a comunicação seja tratada de uma maneira estratégica. Isso pode ser explicado por vários motivos: (a) os meios de comunicação tornaram-se hoje um complexo de veículos e canais, cada um com suas peculiaridades técnicas e de linguagem, cujo uso pressupõe algum conhecimento especializado e uma apreensão de sua lógica de operação; (b) a posse dos meios de comunicação e o acesso a eles se dão de forma assimétrica, sujeitos a interesses nem sempre convergentes e compatíveis com a causa que se deseja defender e (c) para inúmeros conteúdos especializados que compõem a problematização de causas sociais torna-se indispensável uma tradução da fala especializada, de tal maneira que se produza uma informação qualificada, plenamente acessível aos não especialistas (Henriques, S. H, 2002). 
Todos os pontos acima elencados de alguma forma estão presentes no programa de qualificação desenvolvido pela Emater, porem o ponto (c) é o mais marcante, visto que sem a presença dessa linguagem própria evidenciando a cultura local, nenhum dos demais pontos poderiam ser alcançados e desenvolvidos, pois essa linguagem implica numa transmissão de informação que facilita todo o processo, permitindo um maior avanço nessa cadeia de ensino-aprendizagem.

Desde o inicio das atividades do curso de capacitação nos centros de treinamento, em 1995, por volta de 35.000 já foram atendidas. Os impactos sociais promovidos pela realização dos cursos são específicos, porém como o estudo não se deteve somente em um curso e nem em uma das sete regiões onde estão locados os centros, vamos dar uma ênfase de modo geral, evidenciando pontos positivos e o impacto social que esses centros trouxeram para as comunidades rurais do estado do Rio Grande do Sul.

Todas as ações técnicas e sociais desenvolvidas integram um conjunto de políticas públicas voltadas à manutenção das famílias rurais no campo, desenvolvimento rural sustentável, geração de trabalho e renda, com foco na erradicação da pobreza rural e promoção da cidadania.

Desde o início do programa os impactos e mudanças geradas nas comunidades são inúmeras, elas podem ser percebidas a âmbito social e em atendendo todas as faixas etárias. Os cursos voltados ao publico feminino, por exemplo, proporcionaram a inserção da mulher na renda familiar, além de gerar uma maior qualidade de vida. Outro ponto importante a ser mencionado é a inclusão de pessoas portadoras de necessidades especiais, pois com o projeto essas pessoas puderam ter acesso aos cursos, gerando uma nova alternativa de ocupação, melhorando o convívio familiar.

No âmbito geral as atividades geraram novas alternativas de renda para as famílias rurais, motivo que auxilia o agricultor a se manter no campo, influenciando automaticamente seus filhos para que também continuassem, pois com novas alternativas de geração de renda e com o melhor uso da terra, o programa promoveu perspectivas futuras para essas famílias, avivando o processo de (re) criação das famílias rurais e consequentemente sua reprodução social.

A permanência do jovem no campo significa a renovação em diversos aspectos, novas perspectivas de produção e (re) produção e a garantia de que o trabalho realizado pelas famílias continuará gerando resultados pelas mãos dos sucessores. Com essa consciência, estes cursos geraram subsídios, de forma especial, a sucessão familiar e o estímulo à permanência da juventude no espaço rural. Ficando evidente que todos esses fatores trazem mudanças não puramente econômicas, mas principalmente sociais e culturais.

O enfretamento da pobreza no espaço rural foi realizado por meio de estratégias, ações e medidas, com a elaboração, captação, execução e monitoramento de projetos de inclusão produtiva, geração de renda, articulados com diferentes parceiros e políticas públicas. Isso gerou a promoção da igualdade de gênero, colaborando para a eliminação das discriminações entre sexos, sempre trabalhando pela equidade de oportunidades dessas pessoas.

Esses pontos estão diretamente ligados à promoção da qualidade de vida que foi alterada devido ao apoio e ao estimulo dado a essas pessoas, por meio do desenvolvimento das diversas atividades que visam à qualidade de vida das famílias, à integração entre as gerações e à valorização da ruralidade. Outro ponto alcançado foi à inclusão produtiva valorizando e apoiando as diversas formas produtivas das famílias rurais, pois nesses programas foram executadas ações que vão desde a produção da matéria-prima até o consumidor final, visando o trabalho, à renda e à qualidade de vida.

Um ponto importante a ser ressaltado é a geração de novas alternativas de ocupação de áreas que antes eram obsoletas, a maioria devido a sua grande declividade. Com os cursos de capacitação voltados à silvicultura e fruticultura, os agricultores passaram a utilizar essas áreas para o plantio de espécies arbóreas e frutíferas, que com pouco investimento inicial geram grandes lucros futuros. Nas áreas mais planas de fácil ocupação, pode-se dar continuidade as atividades que já eram exercidas anteriormente, aumentando a rentabilidade, por meio de praticas mais modernas e viáveis economicamente, porem sempre voltadas a uma agricultura de base ecológica.

Com essas praticas voltadas a preservação dos agroecossitemas, alguns impactos ambientais foram visivelmente amenizados, As praticas e princípios agroecológicos trabalhadas durante os cursos, gerou um aumento na utilização de técnicas menos nocivas ao ambiente como o uso de biofertilizantes nas lavouras, diminuindo as aplicações de insumos químicos.

É importando ressaltar que isto não seria possível se não houvesse o acompanhamento periódico do extensionista ao agricultor. Os agentes continuam a manter contato com o produtor e realizando 
emissões de relatórios técnicos que trazem informações e dados dos resultados e andamento das atividades obtidas pelos agricultores, ponto primordial para o sucesso do empreendimento, garantindo o bem estar futuro, e não somente momentâneo.

\section{CONCLUSÃO}

Com o presente estudo pode-se concluir que estes centros de capacitação de agricultores estão obtendo os resultados esperados, segundo a análise feita este ponto deve-se principalmente ao fato de que os profissionais da área dirigidos pela EMATER, usam uma linguagem simples, clara e comum aos agricultores locais, bem como em todo o processo de aprendizagem os extensionistas procuram relacionar o referencial teórico com a realidade dos produtores rurais, mantendo sempre uma mídia primária forte e dominante esses centros veem trazendo resultados extremamente eficientes.

\section{REFERÊNCIAS}

BAITELLO JUNIOR, Norval. O tempo lento e o espaço nulo: Mídia primária, secundária e terciária. Associação Nacional dos Programas de Pós-Graduação em Comunicação. São Paulo, 1993.

BRASIL. Empresa de Assistência Técnica e Extensão Rural-RS. Disponível em: $<$ http://www.emater.tche. $\mathrm{br} / \mathrm{site} /$ index.php $>$. Acesso em 21 de maio de 2014.

EMATER/ASCAR. Programa de qualificação profissional de agricultores (regional Ijuí). Ijuí, 2006. 10p. (Relatório técnico).

EMATER/ASCAR. Programa de qualificação profissional de agricultores (regional Erechim). Erechim, 2008. 10p. (Relatório técnico).

EMATER/ASCAR. Programa de qualificação profissional de agricultores (regional Caxias do Sul). Caxias do Sul, 2009. 10p. (Relatório técnico).

FREIRE, Paulo. Pedagogia do Oprimido. $17^{\circ}$ ed. Paz e Terra: Rio de Janeiro, 1987.

HENRIQUES, Márcio S. et. alii. Comunicação e Estratégias de Mobilização Social.2.ed. Belo Horizonte: Autêntica, 2004.

HENRIQUES, Márcio S, BRAGA, Clara S. SILVA, Daniela. B, C. MAFRA, Rennan, L, M. Comunicação e Estratégias de Mobilização Social. 2.ed. Belo Horizonte: Autêntica, 2002.

TORO, José B. \& WERNECK, Nísia M. D. Mobilização Social: um modo de construir a democracia e a participação. 2.ed. Belo Horizonte: Autêntica, 2004.

TUFTE. Thomas. O renascimento da Comunicação para a transformação social - Redefinindo a disciplina e a prática depois da 'Primavera Árabe'. Intercom. São Paulo, v.36, n.2, p. 61-90, jul./dez. 2013. 